\title{
ÇKKV Yöntemleri İle İmalat İşletmelerinde TZY Performans Faktörlerinin Önem Derecelerinin Belirlenmesi ve En İdeal Rekabet Stratejisi Seçimi: Ordu İli Örneği
}

\author{
Selçuk KORUCUK ${ }^{1}$
}

\begin{abstract}
Öz
Tedarik Zinciri Yönetimi (TZY) performans faktörleri uygulanabilir ve verimli bir işletme faaliyeti gerçekleştirmek için hayati derecede öneme sahiptir. TZY performans faktörleri maliyet, kalite, esneklik, lojistik seviyesi, bilgi paylaşımı gibi unsurlara doğrudan etki etmesi sebebi ile işletmeler açısından oldukça önemlidir. Öte yandan işletmeye uygun rekabet stratejisi seçimi, pek çok karar problemini içinde barındıran bir çeşit Çok Kriterli Karar Verme (ÇKKV) problemidir. Dolayısıla böyle bir durumda ÇKKV yöntemlerinin uygulanması tercih edilmektedir. Bu çalışmada; Ordu ili'nde 50 ve üzeri çalışanı olan imalat işletmelerinde SWARA temelli ARAS ve COPRAS yöntemleri ile TZY performans faktörlerinin önem dereceleri ortaya konulmuş ve en ideal rekabet stratejisi seçimi yapılmıştır. Yapılan değerlendirme sonucunda TZY performans unsurlarından en önemlisi "esneklik" faktörü olmuştur. Diğer taraftan hem ARAS hem de COPRAS yönteminde "Odaklanma stratejisi” nin en ideal rekabet stratejisi olduğu sonucuna ulaşılmuştır.
\end{abstract}

Anahtar Kelimeler: TZY, TZY Performans Faktörleri, Rekabet Stratejileri, SWARA, ARAS, COPRAS.

JEL Sinıflandırma Kodlart: C61, MI1.

\section{The Determination of The Importance Rate of The SCM Performance Factors in The Manufacturing Operations With The MCDM Methods and The Best Ideal Competitive Strategy Selection: Case of Ordu Province}

\begin{abstract}
Supply chain management (SCM) performance factors are vital to achieving an applicable and efficient business activity. SCM performance factors are very important for businesses as they have direct impact on cost, quality, flexibility, logistics level, information sharing. On the other hand, choosing a competitive strategy suitable for the business is a kind of multi-criteria decision making (MCDM) problem that includes many decision problems. Therefore, in such a case, the application of the methods of MCDM is preferred. In this study, the importance of SWARA based ARAS and COPRAS methods and SCM performance criteria were determined and the most ideal competition strategy selection was made in manufacturing enterprises with 50 or more employees in Ordu province. As a result of the evaluation, the most important of the performance elements of SCM was the "flexibility" factor. On the other hand, both "ARAS" and "COPRAS" method have achieved "Focus strategy" as the most ideal competition strategy.
\end{abstract}

Key Words: SCM, SCM Performance Factors, Competition Strategies, SWARA, ARAS, COPRAS

1 Dr. Öğr. Üyesi, Giresun Üniversitesi, Bulancak Kadir Karabaş Uygulamalı Bilimler Yüksekokulu, 


\section{S. KORUCUK}

JEL Codes: C61, MI1.

\section{GİRIŞ}

Küreselleşme olgusu ile birlikte son yüzyılda teknolojik, ekonomik, sosyal yani hemen hemen her süreçte çeşitli gelişmeler ve değişmeler yaşanmıştır. Bu değişim ve gelişmeler beraberinde TZY performans unsurları olan maliyet, kalite, esneklik, etkinlik vb. konuları her sektör için önemli kılmış ve rekabet avantajı sağlamada bu kavramların sürdürülebilir hale getirilmesi zorunlu hale gelmiştir. Özellikle imalat işletmeleri için rekabet avantajı sağlamanın önemli göstergelerinden biri şüphesiz TZY performans faktörlerinin başarısına bağlıdır.

Bu kapsamda Beamon (1999), Chan (2003), Tao (2009), TZY performans faktörlerini genel anlamda; maliyetler (dağıtım, üretim, stok vb. maliyetler), kalite (hazırlık süresi, zamanında teslimat, doğruluk vb.), esneklik (malzeme taşıma, hacim, tedarik, teslim vb.), lojistik seviyesi (stok devir hızı, taşıma kayıp oranı, depo kullanım oranı vb.), müşteri memnuniyeti (sipariş tamamlama ve birikme oranı, sürekli müşteri oranı vb.), güven (tutarlılık, işbirliği vb.), yenileşme düzeyi (yeni üretim teknikleri, yeni teknolojilerin kullanımı vb.), bilgi paylaşımı (bilginin zamanında ve doğru iletimi, bilgi kullanım oranı, tedarikçiler ile entegrasyon vb.) ve kaynak kullanımı (personeli makine, enerji vb.) olarak ifade etmişlerdir. Bu faktörler rekabet avantajı sağlamada önemli unsurları olmakla birlikte sürdürülebilir bir rekabet anlayışı oluşturmada etkin rekabet stratejilerini gerektirmektedir.

Rekabet stratejileri; işletmelerde rekabetin temel oluşturduğu bir endüstride uygun bir rekabet pozisyonu elde etmek için çaba harcamasıdır.(Cantürk, 2016: 101) Bu kavramı ilk kez Porter (1980) yılında kullanmış genel olarak 3 farklı rekabet stratejisinden söz etmiştir. Bu stratejiler toplam maliyet liderliği, farklılaştırma ve odaklanma stratejileridir.( Porter, 1998: 35) 
Toplam maliyet liderliği, müşteri memnuniyeti, hizmet, kalite vb. alanları göz önüne alarak maliyetleri rakip firmalardan daha düşük oranda gerçekleştirmektir. (Dess ve diğ., 1984: 469) Farklılaştırma stratejisi ise, firmaların müşteriler için sunduğu ürün ya da hizmetlerden herhangi birisinin farklılaştırmasıdır. $\mathrm{Bu}$ olgu teknoloji, marka kimliği, müşteri hizmet seviyesi ve tasarım şeklinde olabilir. Eğer bu strateji başarılı bir biçimde işletme içerisinde uygulanmışsa işletmeye ortalamanın üzerinde bir getiri sunabilir. Çünkü müşteriler fiyata karşı düşük duyarlıl1k gösterir ve marka sadakati sebebiyle rakiplere karşı rekabet avantajı sunar aynı zamanda elde edilen müşteri sadakati ile benzersiz ürünler sektöre yeni girenler için bir engel oluşturur (Porter, 1998: 37).

Odaklanma stratejisi de, belirli ve sınırlı bir müşteri kitlesi ya da pazar ihtiyaçlarını karşılamaya yönelik rekabet stratejilerindendir. Bu strateji coğrafi pazar olarak, müşteri grubu ya da ürün yelpazasinin bölümlendirilmesiyle, belirli bir pazarda mal veya hizmet üzerine yoğunlaşmak olarak düşünülebilir. Müşteri türüne göre bir pazar seçilerek yaşlı, genç, zengin, maceracı diye bir pazar sınırlandırılması yapılabilir. Ürün hattının belirli bir kesimine yoğunlaşmak için hızlı arabalar, vejetaryen ürünler, giysi tasarımı ve güneş gözlüğü olmak üzere sadece tek bir ürün hattına da yönelebilir (Hill vd., 2009: 117).

Porter'nn ileri sürdüğü rekabet stratejilerine ek olarak birleşik rekabet stratejisi ve yenileşme stratejisi günümüzde ortaya atılan diğer stratejilerdendir. $\mathrm{Bu}$ kapsamda birleşik rekabet stratejisi işletmeler için ana rekabet stratejilerini veya odaklanmış stratejilerden iki ya da daha fazlasını aynı anda veya birbirine yakın aralıklarla uygulanması olarak ifade edilmiştir ( Ülgen ve Mirze, 2004: 269)

Oflazoğlu ve Koçak (2012) çalışmasında ise yenilik stratejisini pazarda marka bağımlılığı oluşturan, kaliteli ve taklitsizlik sağlayan hem müşteri memnuniyeti hem de firma kârlılığını arttıran hizmet ve pazar farklılaştırma stratejileri olarak görmekte, rakiplerine üstünlük sağlamada ve dinamik çevre koşullarına ayak uydurmada rekabetçi avantaj elde etmede önemli unsurlar olarak saymaktadır. 


\section{S. KORUCUK}

Ayrıca, bu avantajı devam ettirmede yenilik stratejisi de önemli bir uzun vadeli rekabet stratejisidir. Dahası stratejik yönlülüklerin yenilik ve firma performansı üzerinde etkisi olumludur. Nihayet, yenilik ve yenilikçilik seviyesinin artması firmaların performansını arttırmaktadır.

Çalışmada TZY performans için belirlenen faktörler ve en ideal rekabet stratejisi seçimi SWARA temelli ARAS ve COPRAS yöntemleri ile gerçekleştirilmiştir. Çalışmanın amacı işletmeler için çok önemli bir yeri olan TZY performans faktörlerinin ağırlıkları SWARA yöntemi kullanılarak elde edilmiş ve elde edilen ağırlıklar kullanılarak ARAS ve COPRAS yöntemleri ile ayrı ayrı en ideal rekabet stratejisi seçiminin sıralaması en iyi olandan en kötüye doğru gerçekleştirilmiştir.

Çalışma beş bölümden oluşmaktadır. İkinci bölümde SWARA, ARAS ve COPRAS yöntemleri üzerine yapılmış bazı çalışmalara yer verilmiştir. Sonraki bölümde SWARA, ARAS ve COPRAS yöntemleri anlatılmıştır. Dördüncü bölümde SWARA, ARAS ve COPRAS yöntemlerinin nasıl uygulandığına ilişkin bir örnek uygulamaya yer verilmiştir. Son bölüm ise sonuç ve önerileri içermektedir.

\section{LITERATÜR TARAMASI}

Çok Kriterli Karar Verme Yöntemlerinden olan SWARA, ARAS ve COPRAS yöntemleri birçok sektör ve işletme için kullanılan sıklıkla başvurulan değerlendirme, sıralama ve seçme araçlarındandır. Bu doğrultuda bu çalışmalardan bazıları aşağıda Tablo 1.'de özetlenmiştir.

Tablo 1. SWARA, ARAS ve COPRAS Yöntemleri İle İlgili Literatür Özeti

\begin{tabular}{|l|l|}
\hline \multicolumn{2}{|c|}{ SWARA Yöntemi İle İlgili Yapılan Çalışmalar } \\
\hline Uyuşmazlık çözüm yöntemi & Keršuliene vd., (2010) \\
\hline Tedarikçi seçimi & Alimardani, vd., (2013) \\
\hline $\begin{array}{l}\text { Pazar bölümlenmesi ve Pazar bölümü değerlendirmesi } \\
\text { ve seçimi }\end{array}$ & Aghdaie, vd., (2013) \\
\hline Yatırım önceliklendirme & Zolfani ve Bahrami, (2014) \\
\hline Güneş enerjisi santrallerinin kurulacağı bölge seçimi & Vafaeipour vd., (2014) \\
\hline
\end{tabular}




\begin{tabular}{|c|c|}
\hline AR-GE proje seçimi & Nezhad, vd., (2015) \\
\hline Sera yeri seçimi & Kouchaksaraei vd., (2015) \\
\hline Otel seçimi & $\begin{array}{l}\text { Tuş Işık ve Aytaç Adalı, } \\
\text { (2016) }\end{array}$ \\
\hline Müteahhit seçimi & Çakır, (2016) \\
\hline $\begin{array}{l}\text { Sürdürülebilir üçüncü parti ters lojistik sağlayıcı } \\
\text { seçimi }\end{array}$ & Mavi vd., (2017) \\
\hline Sunucu seçimi & $\begin{array}{l}\text { Yurdoğlu ve Kundakc1 } \\
\text { (2017) }\end{array}$ \\
\hline $\begin{array}{l}\begin{array}{l}\text { Türkiye'deki } \\
\text { belirlenmesi }\end{array} \\
\end{array}$ & $\begin{array}{l}\text { Ayy1ldiz ve Demirci, } \\
(2018)\end{array}$ \\
\hline \multicolumn{2}{|c|}{ ARAS Yöntemi İle İlgili Yapılan Çalıșmalar } \\
\hline Bina inşa yerinin belirlenmesi & Zavadskas vd., (2010) \\
\hline Köprü yapımı için büyük kazıkların seçimi & Sušinskas vd., (2011) \\
\hline Personel seçimi & Dadelo vd., (2012) \\
\hline Materyal seçimi & $\begin{array}{l}\text { Chatterjee ve Chakraborty, } \\
(2013)\end{array}$ \\
\hline Enerji üretim teknolojileri seçimi & Sliogeriene vd., (2013) \\
\hline $\begin{array}{l}\text { Tarihi binaların korunması için öncelikli alternatiflerin } \\
\text { seçimi }\end{array}$ & Kutut vd., (2014) \\
\hline Konut alternatiflerinin seçimi & Yildırım, (2015) \\
\hline Kurumsal kaynak planlaması yazılım seçimi & Ecer, (2016) \\
\hline Lojistik işletmelerinde en uygun araç seçimi & Arslan, (2017) \\
\hline $\begin{array}{llll}\begin{array}{l}\text { Yaşam kalitesi } \\
\text { değerlendirilmesi }\end{array} & \text { açsından } & \text { AB } & \text { ülkelerinin } \\
\end{array}$ & Ömürbek vd., (2017) \\
\hline \multicolumn{2}{|c|}{ COPRAS Yöntemi İle İlgili Yapılan Çalışmalar } \\
\hline Müteahhit işletme seçimi & Kaklauskas vd., (2006) \\
\hline Yatırım projesi seçimi & Popovic, vd., (2012) \\
\hline $\begin{array}{l}\text { Çok yaşayan evlerde ekonomik modernleşme } \\
\text { değerlendirmesi }\end{array}$ & Staniunas vd., (2013) \\
\hline Takım tezgâh seçimi & Nguyen vd., (2014) \\
\hline Kömür işletmeleri performans değerlendirmeleri & Aksoy vd., (2015) \\
\hline Fiyat konut sürdürülebilirliğinin belirlenmesi & Mulliner vd., (2016) \\
\hline Girişim sermayesi yatırım ortalıklarının ölçümü & Uygurtürk, (2016) \\
\hline Derin temel kazı projesinde risk değerlendirme & Valipour vd., (2017) \\
\hline Malzeme seçimi & $\begin{array}{l}\text { Mousavi-Nasab ve } \\
\text { Sotoudeh-Anvari, (2017) }\end{array}$ \\
\hline Nakit akışına dayalı performans ölçümü & Kaplanoğlu, (2018) \\
\hline
\end{tabular}

Yapılan literatür taramasında TZY performans faktörlerinin önem derecelerinin belirlenmesi ve en ideal rekabet stratejisi seçimine ilişkin başkaca bir çalışma tespit 


\section{S. KORUCUK}

edilmemiştir. $\mathrm{Bu}$ olgu çalışmanın önemini artıran bir unsur olarak düşünülmektedir. Ayrıca TZY performans faktörleri ile rekabet stratejileri konusunda SWARA-ARAS ve SWARA-COPRAS bütünleşik yaklaşımlarının kullanıldığı bir çalışmaya da rastlanmamıştır. Bu nedenle bu çalışmanın literatüre katkı sağlayacağı değerlendirilmektedir.

\section{ARAŞTIRMANIN YÖNTEMI}

Ordu ili'nde 50 ve üzeri çalışanı olan imalat işletmelerinde TZY performans faktörlerinin önem derecelerinin belirlenmesinde Çok Kriterli Karar Verme (ÇKKV) yöntemi olan SWARA'dan faydalanılmış ve kriter ağırlıkları SWARA ile belirlenmiştir. İlerleyen aşamada ise belirlenen ağırlıklar kullanılarak en ideal rekabet stratejisi seçiminde hem ARAS hemde COPRAS yönteminden yararlanılmıştr.

$\mathrm{Bu}$ bölümde TZY performans faktörleri için belirlenen kriterlerin değerlendirilmesi kullanılan SWARA ile en ideal rekabet stratejisi seçiminde kullanılan iki ayrı yöntem olan ARAS ve COPRAS anlatılmıştır.

\subsection{SWARA Yöntemi}

SWARA yöntemi kriterlerin ve alternatiflerin dilsel ifadelerle değerlendirilmesi sürecinde yer alan belirsizliklerin üstesinden gelmek için kullanılan Çok Kriterli Karar Verme yöntemlerinden biridir (Alimardani vd., 2013: 542). Karar verme problemlerinde SWARA yönteminin temel avantaj1, karar verme problemlerini çözmede, kriterleri suralamak için herhangi bir değerlendirmeye ihtiyaç duymadan, kriter önceliklerini işletmelerin stratejilerine veya planlarına ya da ülkelerin politikalarına dayalı olarak belirleyebilmesidir (Kouchaksaraei vd., 2015: 115).

$\mathrm{Bu}$ doğrultuda SWARA yönteminin temel adımları şunlardır (Ruzgys vd., 2014: 107; Stanujkic vd., 2015: 182);

Adım 1: Kriterlerin sıralanması:

Kriterler, uzman görüşü doğrultusunda önem sırasına göre azalan düzende basit olarak sıralanır. Eğer birden çok uzman kriterleri değerlendirecekse, her bir 
uzmanın münferiden yaptığı değerlendirme sonucu kriterler azalan düzeyde sıralanır ve kriterlerin geometrik ortalaması alınarak genel bir sıralama oluşturulur.

Adım 2: Her bir kriterin göreli önem düzeyinin belirlenmesi:

Bunun için $j$. kriter $(j+1)$ kriterle kıyaslanarak $j$. kriterin $(j+1)$. kriterden ne kadar önemli olduğu belirlenir. Bu kıyaslama için Keršuliene vd. (2010) tarafından önerilen değişken $s_{j}$ ile gösterilmiş ve "ortalama değerin karşılaştırmalı önemi" olarak adlandırılmıştır.

Adım 3: $k_{j}$ katsayısının belirlenmesi:

$k_{j}$ katsayısı Denklem (1) kullanılarak hesaplanır.

$$
k_{j}= \begin{cases}1 & j=1 \\ s_{j}+1 & j>1\end{cases}
$$

Adım 4: $q_{j}$ değişkeninin hesaplanması:

$q_{j}$ değişkeni Denklem (2) kullanılarak hesaplanır.

$$
q= \begin{cases}1 & j=1 \\ \frac{q_{j-1}}{k_{j}} & j>1\end{cases}
$$

Adım 5: Kriter Önem Derecelerinin Belirlenmesi:

Değerlendirme kriterlerinin göreli ağırlıkları Denklem (3) kullanılarak hesaplanır. $w_{j}, j \times$ kriterin göreli ağırlığını belirtir.

$$
w_{j}=\frac{q_{j}}{\sum_{k=1}^{n} q_{k}}
$$

\subsection{ARAS YÖNTEMI}

Zavadskas ve Turksis (2010) tarafindan geliştirilen ARAS yöntemi her bir seçeneğin en uygun seçeneğe göre oransal benzerliğini ortaya çıkarmaktadır (Dadelo - Turskis, vd., 2012: 68). Öte yandan yöntem diğer Çok Kriterli Karar 


\section{S. KORUCUK}

Verme Yöntemlerinden farklı bir yapıya sahiptir. Bu yöntemde seçeneklerin fayda fonksiyonu araştırmacı tarafından karar problemine optimal seçeneklere ait fayda fonksiyonu değerleri ile karşılaştırma imkanı vermektedir. (Sliogeriene - Turskis, vd., 2013: 13). Bu çerçevede ARAS yönteminin aşamaları aşağıda verilmiştir. (Zavadskas - Turskis, 2010: 163-165)

Adım 1. Karar Matrisinin Oluş̧urulması:

$\mathrm{Bu}$ yöntemde başlangıç karar matrisinden her bir kritere ait optimal değerlerden oluşan bir satır yer alır.

$\mathrm{X}=\left[\begin{array}{cccc}X_{01} & X_{02} & \cdots & X_{0 n} \\ X_{11} & X_{12} & \cdots & X_{1 n} \\ \vdots & \vdots & \cdots & \vdots \\ X_{m 1} & X_{m 2} & \cdots & X_{m n}\end{array}\right] ; \quad i \quad=0,1,2, \ldots, \mathrm{m} \quad$ ve $\quad \mathrm{j}=1,2, \ldots, \mathrm{n}$ (4)

Kriterlere ait optimal değer, karar probleminde belli değil ise, ilgili kriter maksimum ya da minumum özelliği göstermesi halinde, optimal değer eşitlik (5) sayesinde hesaplanır.

$\left\{\begin{array}{c}E \text { ğer } \text { maksix }_{i j} \text { ise } x_{o j}=\text { maksix }_{i j} \\ \text { Ĕger } \text { minsix }_{i j} * \text { ise } x_{o j}=\text { minsix }_{i j} *\end{array}\right.$

Adım 2: Karar Matrisinin Normalize Edilmesi:

Genellikle ölçütlerin boyutları farklı olmakta dolayısıyla ölçütlerin boyutsuz değerleri hesaplanmalıdır. Normalizasyon sürecinde ölçütler maksimizasyon yönlü ise normalize işlemi eşitlik (6) göre yapılır (Özbek, 2017: 60).

$x_{i j}=\frac{x_{i j}}{\sum_{i=0}^{m} x_{i j}}$

Ölçütlerin minimizasyon yönlü olması durumunda iki aşamalı olarak (7) numaralı eşitlik kullanılarak hesap edilir (Özbek, 2017: 61).

$x_{i j}=\frac{1}{x_{i j} *} ; \quad x_{i j}=\frac{x_{i j}}{\sum_{i=0}^{m} x_{i j}}$

Adım 3: Ağırlıklandırılmış Normalize Edilmiş Karar Matrisinin Oluşturulması

Karar matrisi normalize edildikten sonra belirlenen $w_{j}$ ağırlıkları kullanılarak $\mathrm{x}$ ağılıklandırılmış normalize karar matrisi oluşturulur. Kiriter ağırlık değerleri $0<\mathrm{w}_{\mathrm{j}}<1$ şeklinde olup eşitlik (8) gösterilmiştir. 
$\sum_{j=1}^{n} w_{j}=1$

Öte yandan eşitlik (9) sayesinde normalize değerler kullanılarak $x_{i j}$ ağırlıklandırılmış normalize değerler elde edilir.

$\boldsymbol{x}_{i j}=\boldsymbol{x}_{i j} w_{j} \quad \mathrm{j}=0,1, \ldots, \mathrm{m}$

Adım 4: Optimal Değerlerin Hesaplanmas1

(10) numaralı eşitlikten faydalanılarak her karar seçeneğinin optimal değeri hesaplanir.

$$
=\sum_{j=1}^{n} x_{i j} ; \quad \mathrm{i}=0,1, \ldots, \mathrm{m}
$$

ve $\quad \mathrm{j}=1,2, \ldots ., \mathrm{n}$

Adım 5: Fayda Derecelerinin Hesaplanması ve Siralamanın Elde Edlmesi:

Bu durum eşitlik (11) yardımı ile hesaplanır.

$K_{j}=\frac{\mathrm{Sj}}{\mathrm{So}} ; \mathrm{i}=0,1, \ldots, \mathrm{m}$

\subsection{COPRAS YÖNTEMI}

1996 yılında Zavadskas ve Kaklauskas tarafından geliştirilen yöntem karmaşık oransal değerlendirme ile aynı zamanda kriterlerin fayda ve önem unsurları bakımından seçeneklerin değerlendirilmesi ve sıralanması için kullanılır. Öte yandan kriter değerleri ölçüt değerlendirmesinde faydasız kriterleri en aza indirme değerlendirilmesi ve fayda kriterinin üst düzeye çıkartılması için de uygulanır (Podvesko, 2011: 137). COPRAS yönteminin işlem adımları aşağıda verilmiştir (Zavadskas vd, 2008: 242-243: Podvezko, 2011: 138-139).

Adım 1. Karar Matrisinin Oluşturulması

COPRAS yönteminde ilk aşamasında karar matrisi oluşturulur ve eşitlik (12) 'de gösterildiği gibi formüle edilir. 


\section{S. KORUCUK}

$x_{i j}=\left[\begin{array}{llll}X_{11} & X_{12} & X_{13} & X_{1 n} \\ X_{21} & X_{22} & X_{23} & X_{2 n} \\ X_{31} & X_{32} & X_{33} & X_{3 n} \\ X_{m 1} & X_{m 2} & X_{m 3} & X_{m n}\end{array}\right]$

Adım 2. Normalize Edilmiş Karar Matrisinin Oluşturulması

Normalize edilmiş karar matrisi eşitlik (13) yardımıyla hesaplanır.

$x_{i j}=\frac{x_{i j}}{\sum_{i=1}^{m} x_{i j}} \forall \mathrm{j}=1,2, \ldots n$

Adım 3.Ağırlıklı Normalize İndekslerin Toplanması

$\mathrm{Bu}$ aşamada normalize edilmiş karar matrisi sütunlarının kriterlere verilen $\mathrm{w}_{\mathrm{j}}$ ağırlık değerleri ile çarpılır ve eşitlik (14) yardımı ile hesaplanır.

$\mathrm{D}^{\prime}=d_{i j}=x_{i j}{ }^{*} . \mathrm{w}$

Adım 4. Faydalı ve Faydasız Ölçütlerin Hesaplanması

Faydalı ölçütler hesaplanırken eşitlik (15)’ten yararlanılır.

$\mathrm{S}_{\mathrm{i}}^{+} \sum_{j=1}^{k} d_{i j} \quad \mathrm{j}=1,2, \ldots, \mathrm{n}$

Faydasız ölçütlerşn hesaplanmasında ise eşitlik (16)'dan yararlanılır.

$\mathrm{S}_{\mathrm{i}}^{-} \sum_{j=\mathrm{k}+1}^{k} d_{i j} \quad \mathrm{j}=\mathrm{k}+1, \mathrm{k}+2, \ldots ., \mathrm{n}$

Adım 5. Seçeneklerin Göreceli Öneminin Hesaplanması

Her bir seçenel için göreceli önem değerleri eşitlik (17)'den faydalanılarak hesaplanır.

$Q i=S_{i}+\frac{\sum_{i=1}^{m} \mathrm{Si}_{-}}{\mathrm{Si}_{-} \cdot \sum_{i=1}^{m} \frac{1}{\mathrm{Si}-}}$

Adım 6. En Yüksek Göreceli Önem Değerlerinin Hesaplanması

En yüksek göreceli önem değeri eşitlik (18)'den yararlanılarak hesaplanır. 
$\mathrm{Q}_{\max }=\operatorname{enbüyük}\left\{\mathrm{Q}_{\mathrm{i}}\right\} \forall_{\mathrm{i}}=1,2, \ldots \mathrm{m}$

Adım 7. Alternatiflerin Fayda Derecelerinin Belirlenmesi

Alternatiflerin fayda derecesi eşitlik (19) ile hesaplanır ve fayda derecesi 100 olan alternatif en iyi seçenek olmaktadır.

$\mathrm{P}_{\mathrm{i}}=\frac{\mathrm{Qi}}{Q \max } x 100 \%$

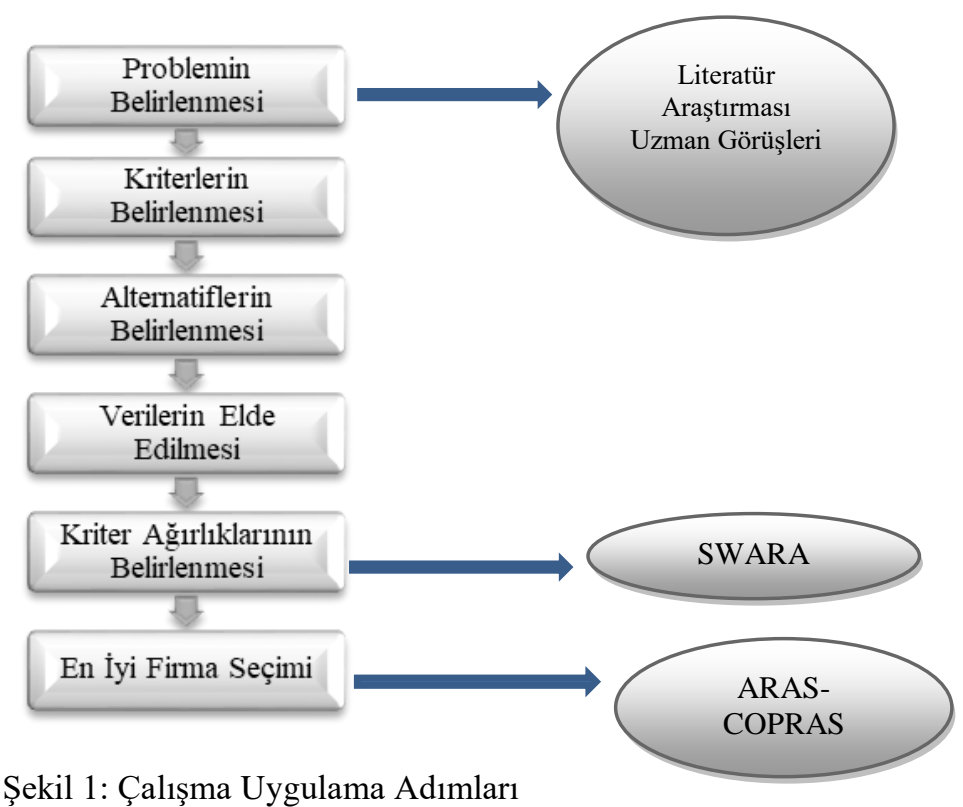

\section{UYGULAMA}

Çalışmada Ordu ili'nde TZY performans sürecinde kullanılacak faktörlerin değerlendirilmesi için çok kriterli karar modeli oluşturulmuştur. Şekil 1'de verilen modelin adımları uygulanmıştır. Modele göre öncelikle uzman görüşleri ile literatür taramasından faydalanılarak TZY performans faktörleri belirlenmiştir. Belirlenen kriterler eşit öneme sahip olmadığından faktörlerin ağırlıklandırılmasına ihtiyaç duyulmuştur. $\mathrm{Bu}$ kapsamda SWARA yöntemi ile TZY performans faktörleri ağırlıklandırılmıştır. Ardından belirlenen ağırlıklar kullanılarak ARAS ve COPRAS yöntemleri ile en ideal rekabet stratejisi seçimi yapılmıştır. 


\section{S. KORUCUK}

Kriterler belirlenirken uzman görüşleri, literatür taraması, akademisyenler ve işletme yöneticilerinden yararlanılarak aşağıdaki Tablo. 2 oluşturulmuştur.

Tablo 2. Karar Kriterleri

\begin{tabular}{|c|c|}
\hline Ana Kriterler & Kaynak \\
\hline Maliyetler (Dağıtım, Üretim, Stok vb. maliyetler) $\left(\mathrm{K}_{1}\right)$ & $\begin{array}{l}\text { Chan (2003), Gunesekaran ve } \\
\text { Kobu (2007), Tao (2009). }\end{array}$ \\
\hline $\begin{array}{l}\text { Kalite (Hazırlık Süresi, Zamanında Teslimat, Doğruluk } \\
\text { vb.) }\left(\mathrm{K}_{2}\right)\end{array}$ & $\begin{array}{l}\text { Chan (2003), Uzman } \\
\text { Görüşleri }\end{array}$ \\
\hline $\begin{array}{l}\text { Esneklik (Malzeme Taşıma, Hacim, Tedarik, Teslim vb.) } \\
\left(\mathrm{K}_{3}\right)\end{array}$ & Beamon (1999), Chan (2003). \\
\hline $\begin{array}{l}\text { Lojistik Seviyesi (Stok Devir Hızı, Taşıma Kayıp Oranı, } \\
\text { Depo Kullanım oranı vb.) }\left(\mathrm{K}_{4}\right)\end{array}$ & $\begin{array}{l}\text { Tao (2009), Askariazad ve } \\
\text { Wanous (2009). }\end{array}$ \\
\hline $\begin{array}{l}\text { Müşteri Memnuniyeti (Sipariş Tamamlama ve Birikme } \\
\text { Oranı, Sürekli Müşteri Oranı vb.) }\left(\mathrm{K}_{5}\right)\end{array}$ & $\begin{array}{l}\text { Beamon (1999), Uzman } \\
\text { Görüşleri. }\end{array}$ \\
\hline Güven (Tutarlılık, İşbirliği vb.) $\left(\mathrm{K}_{6}\right)$ & Chan (2003), Tao (2009). \\
\hline $\begin{array}{l}\text { Yenileşme Düzeyi (Yeni Üretim } \\
\text { Teknolojilerin Kullanımı vb.) }\left(\mathrm{K}_{7}\right)\end{array}$ & Beamon (1999), Chan (2003). \\
\hline $\begin{array}{l}\text { Bilgi Paylaşımı (Bilginin Zamanında ve Doğru İletimi, } \\
\text { Bilgi Kullanım Oranı, Tedarikçiler ile Entegrasyon vb.) } \\
\left(\mathrm{K}_{8}\right)\end{array}$ & $\begin{array}{l}\text { Beamon (1999), Chan (2003), } \\
\text { Tao (2009). }\end{array}$ \\
\hline Kaynak Kullanımı (Personeli Makine, Enerji vb.) (K9) & $\begin{array}{l}\text { Chan (2003), Uzman } \\
\text { Görüşleri. }\end{array}$ \\
\hline
\end{tabular}

Tablo 3.'de ise rekabet stratejilerine ilişkin alternatifler verilmiştir. Bu araçların belirlenmesi sürecinde literatür taraması ve uzman görüşlerinden yararlanılmıştır. Bu kapsamda genel olarak rekabet stratejileri aşağıdaki Tablo 3.'de sunulmuştur (Porter, 1998: 35, Porter, 2000: 47, Çetinkaya, 2006: 60, Bülbül, 2007: 94, Hill ve Jones, 2009: 117, Barca ve Esen, 2012: 97, Coşkun, vd., 2013: 112, Camison ve Villar-Lopez, 2014: 2895, Cantürk, 2016: 104).

Tablo 3. Rekabet Stratejileri Tablosu

\begin{tabular}{cc}
\hline Seçenekler & Rekabet Stratejileri \\
\hline $\mathrm{A}_{1}$ & Toplam Maliyet Liderliği \\
$\mathrm{A}_{2}$ & Farklılaştırma \\
$\mathrm{A}_{3}$ & Odaklanma \\
$\mathrm{A}_{4}$ & Birleşik Rekabet Stratejileri \\
$\mathrm{A}_{5}$ & Yenileşme \\
\hline
\end{tabular}




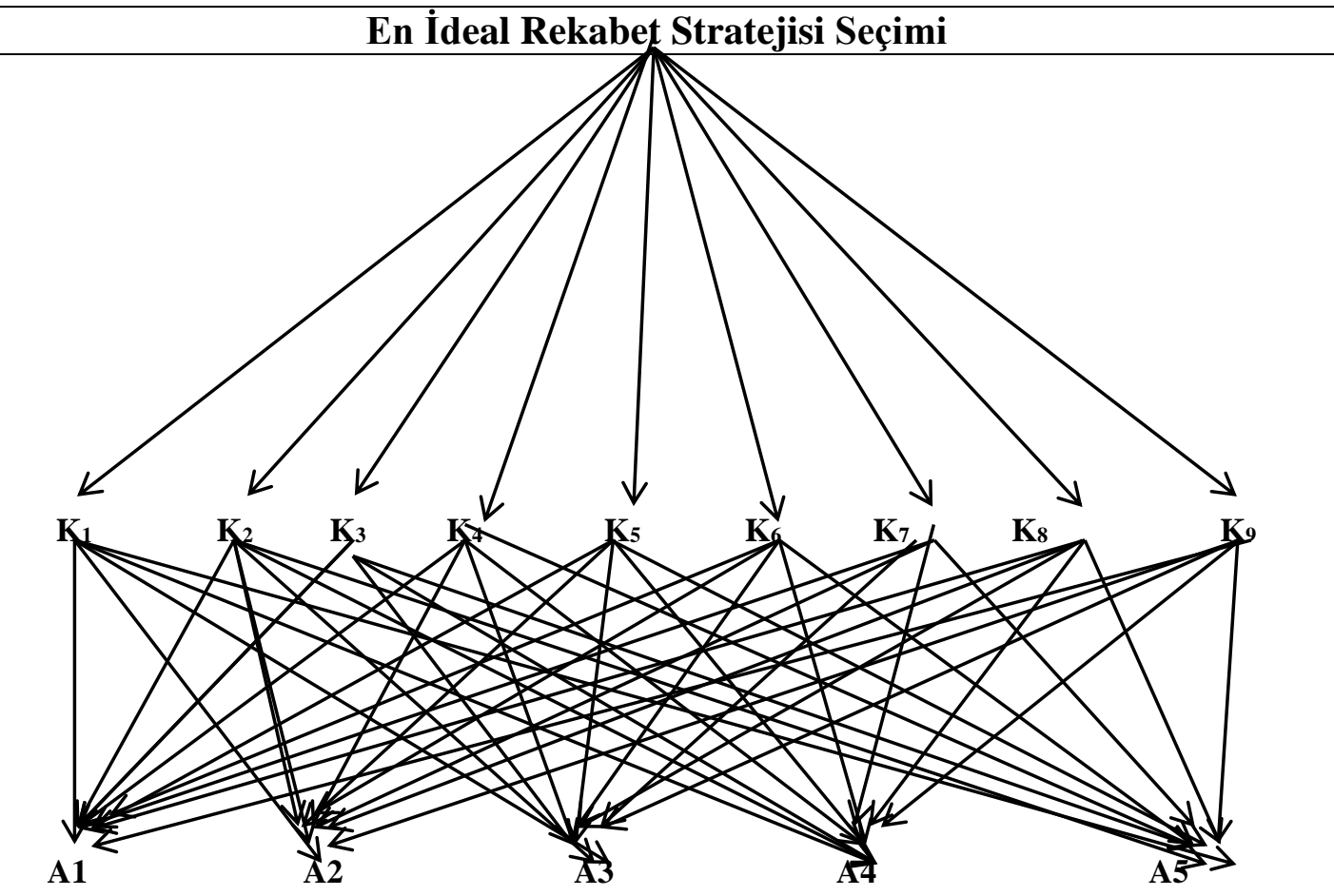

Şekil 2. Hiyerarşik Yapı

\subsection{Kriterlerin Ağırlıklandırılması}

ÇKKV yöntemleri, bir karar sürecine yardımcı olmak için sayısız ve çoğunlukla birbirleri ile çelişen nicel ve nitel ölçütlerin belirlenmesini ve dikkate alınmasını sağlayan, genellikle farklı ölçütlere göre ayrı özelliklere sahip seçenekler kümesinden bir ya da daha fazla seçeneği seçmek, sıralamak ya da sınıflandırmak için gerekli yöntemler topluluğudur (Zopounidis, 1999 :404-405) Verinin türüne göre "stokastik", "bulanık modeller" ve "deterministik" olarak sınıflandırılırken, karar verici sayısına göre "tekli karar verme" ve "grup kararı verme" olarak da sinıflandırılmaktadır (Triantaphyllou, 2000: 175). 


\section{S. KORUCUK}

Dolayısıyla ÇKKV yöntemleri, istatistiksel analizlerde olduğu gibi bir örneklem kütlesinden ana kütleye genelleme yapmak için kullanılan yöntemlerden değildir. $\mathrm{Bu}$ yöntemler sübjektif ve objektif kriterlerin bir arada değerlendirelebildiği ve uzman görüşlerine göre analizin gerçekleştirildiği yöntemlerdendir. Yine bu yöntemlerde bir grup kararına göre değerlendirme olabileceği gibi tek uzman görüşü ile de çalışma şekillenebilir. Bu çalışmada ise, ÇKKV yöntemlerinden SWARA'dan faydalanılmış ve konunun paydaşları olan akademisyenlere (2), 50 ve üzeri çalışanı olan işletme yöneticilerine (10) toplamda 12 uzman görüşü alınarak çalışma şekillendirilmiştir. Görüşlere ilişkin tablolar Ekler kısmında verilmiştir. Bu doğrultuda kriterlerin ağırlıklandırılmasına yönelik olarak SWARA ile ağırlıklar belirlenmiş ve Tablo 4'de yer alan kriter ağırlıkları elde edilmiştir.

Tablo 4. Kriter Ağırlıkları Tablosu

\begin{tabular}{|c|c|c|c|c|c|c|c|c|c|}
\hline & $\mathbf{K}_{\mathbf{1}}$ & $\mathbf{K}_{\mathbf{2}}$ & $\mathbf{K}_{\mathbf{3}}$ & $\mathbf{K}_{\mathbf{4}}$ & $\mathbf{K}_{\mathbf{5}}$ & $\mathbf{K}_{\mathbf{6}}$ & $\mathbf{K}_{\mathbf{7}}$ & $\mathbf{K}_{\mathbf{8}}$ & $\mathbf{K}_{\mathbf{9}}$ \\
\hline Ăğırlık & 0,138 & 0,147 & 0,157 & 0,124 & 0,109 & 0,100 & 0,073 & 0,064 & 0,088 \\
\hline
\end{tabular}

Tablo 4'e göre TZY performans faktörlerinin en önemlileri sırası ile "Esneklik", "Kalite“, "Maliyetler", "Lojistik Seviyesi”, "Müşteri Memnuniyeti” ve "Güven" olduğu saptanmıştır. Öte yandan en az öneme sahip kiriterlerin ise sırasıyla "Bilgi Paylaşımı", "Yenileşme Düzeyi” ve "Kaynak Kullanımı” olduğu tespit edilmiştir.

\subsection{Seçeneklerin Sıralanması}

$\mathrm{Bu}$ bölümde seçeneklerin sıralanması için ARAS ve COPRAS yöntemlerinden yararlanılmıştır. SWARA yöntemi ile elde edilen kriterlerin ağıllıkları kullanılarak ARAS ve COPRAS yöntemleri ile en ideal rekabet stratejisi seçimi yapılarak alternatifler sıralanmıştır. Daha önceden belirlenen karar kriterleri çerçevesinde her bir alternatifin değerlendirilmesi için konunun paydaşları olan akademisyenlere (2), 50 ve üzeri çalışanı olan işletme yöneticilerine (10) toplamda 12 anket uygulanmıştır. $\mathrm{Bu}$ kapsamda her iki ayrı yöntem için ayrı ayrı karar matrisleri oluşturulmuş ve sonrasında karar matrisleri normalleştirilmiştir. Görüşlere ilişkin 
tablolar Ekler kısmında sunulmuştur. Bu kapsamda ARAS yöntemi ile elde edilen sıralama aşağıda Tablo 5.'te verilmiştir.

Tablo 5. ARAS Yöntemi Sıralama Sonuçları

\begin{tabular}{|c|c|c|c|}
\hline & $\mathbf{S j}$ & $\mathbf{K j}$ & Siralama \\
\hline $\mathbf{A} \mathbf{j}$ (Optimal) & 0,211 & 1,000 & Optimal \\
\hline $\mathbf{A}_{\mathbf{1}}$ & 0,157 & 0,744 & 3 \\
\hline $\mathbf{A}_{\mathbf{2}}$ & 0,166 & 0,785 & 2 \\
\hline $\mathbf{A}_{3}$ & 0,168 & 0,793 & 1 \\
\hline $\mathbf{A 4}$ & 0,141 & 0,667 & 5 \\
\hline $\mathbf{A}_{\mathbf{5}}$ & 0,157 & 0,744 & 4 \\
\hline
\end{tabular}

ARAS yönteminin kullanıldığı Tablo 5'e göre en ideal rekabet stratejisi seçimi sıralamasında imalat işletmelerinde $\mathrm{A}_{3}$ "Odaklanma Stratejisi" en ideal rekabet stratejisi olmuştur. Öte yandan en ideal rekabet stratejisi seçimi imalat işletmelerinde genel sıralama ise $A_{3}>A_{2}>A_{1}=A_{5}>A_{4}$ şeklinde gerçekleşmiştir.

Diğer taraftan bir diğer yöntem olan COPRAS ile elde edilen seçeneklerin sıralanması ise aşağıdaki Tablo 6.'da sunulmuştur.

Tablo 6. COPRAS Yöntemi Sıralama Sonuçları

\begin{tabular}{|l|c|c|c|c|c|c|c|c|c|}
\hline & $\mathrm{S}_{+\mathrm{i}}$ & $\mathrm{S}_{\text {-i }}$ & $\mathrm{S}_{\text {-min }}$ & $\mathrm{S}_{\text {-i-Top }}$ & $\begin{array}{c}\mathrm{S}_{\text {-min }} \\
/ \mathrm{S}_{-\mathrm{i}}\end{array}$ & $\begin{array}{c}\mathrm{S}_{\text {-min }} / \\
\mathrm{S}_{\text {-i-Top }}\end{array}$ & $\mathrm{Q}_{\mathrm{i}}$ & $\mathrm{P}_{\mathrm{i}}$ & S1ralama \\
\hline $\mathrm{A}_{1}$ & 0,160 & 0,038 & 0,038 & 0,226 & 1,000 & 4250 & 0,213 & 0,832 & 2 \\
\hline $\mathrm{A}_{2}$ & 0,172 & 0,053 & & & 0,716 & & 0,210 & 0,820 & 3 \\
\hline $\mathrm{A}_{3}$ & 0,211 & 0,044 & & & 0,864 & & 0,256 & 1,000 & 1 \\
\hline $\mathrm{A}_{4}$ & 0,091 & 0,045 & & & 0,844 & & 0,135 & 0,528 & 5 \\
\hline $\mathrm{A}_{5}$ & 0,141 & 0,046 & & & 0,826 & & 0,185 & 0,724 & 4 \\
\hline
\end{tabular}

COPRAS yönteminin kullanıldığı Tablo 6'ya göre en ideal rekabet stratejisi seçimi sıralamasında imalat işletmelerinde $\mathrm{A}_{3}$ "Odaklanma Stratejisi" en ideal rekabet stratejisi olmuştur. Öte yandan en ideal rekabet stratejisi seçimi imalat işletmelerinde genel sıralama ise $A_{3}>A_{1}>A_{2}>A_{5}>A_{4}$ şeklinde gerçekleşmiştir. Her iki yöntem değerlendirildiğinde en önemli rekabet stratejisinin "Odaklanma 


\section{S. KORUCUK}

Stratejisi" olduğu tespit edilmiştir. En az öneme sahip rekabet stratejisi ise her iki yöntem için "Birleşik Rekabet Stratejisi” olduğu belirlenmiştir. Ulaşılan sonuçlar ayrı yöntemler için benzer sonuçları vermesi çalışmanın tuturlılı̆̆ını gösteren bir olgu olarak karşımıza çıkmıştır.

\section{SONUÇ VE ÖNERILER}

Günümüzde işletmeler için rekabet TZY üzerinden gerçekleştirilmekte ve TZY performans ölçümleri çok önemli hale gelmektedir. Çünkü TZY performans faktörleri etkin bir karar mekanizması gerektirmekte dolayısıyla işletmeleri hızla zorlaşan ve giderek değişen piyasa koşullarında sürekli olarak karar vermeye zorlamaktadır. Böylece karar verme problemleri daha karmaşık bir hale gelmekte söz konusu seçeneklere en uygun olanının belirlenmesi Çok Kriterli Karar Verme yöntemlerinden yararlanmayı gerektirmektedir.

Çalışmada ÇKKV yöntemlerinden SWARA, ARAS ve COPRAS yöntemleri göz önüne alınarak, TZY performans faktörleri önceliklendirilmiş ve belirlenen ağırlıklar kullanılarak en ideal rekabet stratejisi seçimi yapılmıştır. $\mathrm{Bu}$ değerlendirmede TZY performans faktörleri; maliyet, kalite, esneklik, lojistik seviyesi, müşteri memnuniyeti, güven, bilgi paylaşımı, yenileşme düzeyi ve kaynak kullanımı olmak üzere toplam dokuz kriter dikkate alınarak yapılmıştır. Ayrıca genel anlamda kabul gören rekabet stratejileri; toplam maliyet liderliği, farklılaştırma, odaklanma, birleşik rekabet stratejileri ve yenileşme olarak belirlenmiştir. Kriterlerdeki ağılıklar kullanılarak en ideal rekabet stratejisi seçimi yapılmış ve sıralanmıştır. İlgili literatür tarandığında böyle bir çalışmaya rastlanmamıştır. $\mathrm{Bu}$ bakımdan çalışma imalat işletmelerini çeşitli açılardan değerlendirilmesine / karşılaştırılmasına örnek nitelikte düşünülebilir. $\mathrm{Bu}$ çalışmada TZY performans faktörleri ağırlıklandırılırken SWARA yönteminden faydalanılmıştır. Kriter ağılıklarına bakıldığında imalat işletmelerinde "Esneklik", "Kalite“, "Maliyetler", "Lojistik Seviyesi”, "Müşteri Memnuniyeti” ve "Güven” faktörlerinin daha önemli kriterler olduğu görünmektedir.

İlerleyen aşamada ARAS ve COPRAS yöntemleri ile en ideal rekabet stratejisi seçimi yapılmıştır. ARAS ve COPRAS yöntemleri sonuçlarına göre; SWARA 
yöntemi ile belirlenen ağırlıklar kullanılarak "Odaklanma" stratejisinin en ideal rekabet stratejisi olduğu tespit edilmiştir. Her iki yöntemin (ARAS-COPRAS) sonuçları kıyaslandığında büyük oranda aynı sonuçlara ulaşılması çalışmanın doğruluğunu ve tutarlılığını artıran bir unsur olarak düşünülebilir. $\mathrm{Bu}$ unsurda işletmelerde ÇKKV yöntemlerinin kullanılmasının uygun olduğunun göstergesi say1lablir.

$\mathrm{Bu}$ çalışmada konunun tarafları olduğu düşünülen uzmanlar ile görüşülmüş ancak zaman kısıtı nedeniyle bu sayı artırılamamıştır. Öte yandan bu çalışmada ele alınan problem başka alanlara da uygulanabilir. Ayrıca söz konusu çalışma gelecekte diğer çok kriterli karar verme ve / veya parametrik veya parametrik olmayan diğer yöntemler ile bulanık mantık ilave edilerek geliştirilebilir ve sonuçlar kıyasalanarak tartışılabilir 


\section{S. KORUCUK}

\section{KAYNAKÇA}

AGHDAIE, M, H, HASHEMKHANI, ZOLFANI, S, ZAVADSKAS, E,K. (2013), "A hybrid Approach for Market Segmentation and Market Segment Evaluation and Selection: An Integration of Data Mining and MADM", Transformations in Business \& Economics, 12(2 B) 431-458.

AKSOY, E, ÖMÜRBEK, N, KARAATLI, M. (2015), “AHP Temelli MULTIMOORA ve COPRAS Yöntemi İle Türkiye Kömür İşletmeleri'nin Performans Değerlendirmesi", Hacettepe Üniversitesi İktisadi ve İdari Bilimler Fakültesi Dergisi,Cilt 33, Say1 4, 1-28.

ASKARIAZAD, M., WANOUS, M. (2009). “A Proposed Value Model For Prioritising Supply Chain Performance Measures, Int. J. Business Performance and Supply Chain Modelling, S. 1 (2), s. 115-128.

ALIMARDANI, M., HASHEMKHANI ZOLFANI, S., AGHDAIE, M. H. VE TAMOŠAITIENÉ, J. (2013), "A Novel Hybrid SWARA and VIKOR Methodology For Supplier Selection İn An Agile Environment", Technological and Economic Development of Economy, 19(3), 533-548.

ARSLAN, H, M, (2017), "AHP-ARAS Hibrit Yöntemi ile Lojistik İşletmelerinin En Uygun Araç Seçimi”, The Journal of Operations Research, Statistics, Econometrics and Management Information SystemsVolume 5, Issue 2, 271-282.

AYYILDIZ, E., DEMİRCİ, E., (2018), “Türkiye'de Yer Alan Şehirlerin Yaşam Kalitelerinin Swara Entegreli Topsıs Yöntemi İle Belirlenmesi”, Pamukkale Üniversitesi Sosyal Bilimler Enstitüsü Dergisi, Say1 30, 67-87.

BARCA, M., ESEN Ş. (2012), "Rekabet Avantaj1 Sağlamada ve Sürdürmede Stratejik Yaklaşımlar", Journal of New World Sciences Academy, 2(7), 89-107.

BEAMON B, M., (1999), "Measuring Supply Chain Performance", International Journal of Operations \&Production Management, S. 19, no.3, 275292.

BÜLBÜL, H. (2007), “Türkiye'deki Büyük Gıda Sanayi Firmalarının Rekabetçi ve Yenilikçi Uygulamaları”, H.Ü. İktisadi ve İdari Bilimler Fakültesi Dergisi, 25 (1), 91-120. 
CANTÜRK, N, (2016). "İşletmelerde Firsat ve Kaynak Tabanlı Yaklaşımların Rekabet Stratejisi Tercihleri ile İlişkisi: Burdur Mermer İşletmlerinde Bir Araştırma", Bartın Üniversitesi, İktisadi ve İdari Bilimler Fakültesi Dergisi, 7/13, 95-121.

CAMISON, C., VILLAR-LOPEZ, A. (2014). Organization Alinnovation as an Enabler of Technological Innovation Capabilities and Firm Performance. Journal of Business Research, 67, 2891-2902.

CHAN, F. T. S. (2003). "Performance Measurement in A Supply Chain", International Journal of Advanced Manufacturing Technology, S. 21, s. 534- 548.

CHATTERJEE, P., CHAKRABORTY, S. (2013). "Gear Material Selection using Complex Proportional Assessment and Additive Ratio Assessmentbased Approaches: A Comparative Study", International Journal of Materials Science and Engineering, 1 (2): 104-111.

COŞKUN, S., MESCİ, M., KILINÇ, İ. (2013). Stratejik Rekabet Üstünlüğü Sağlama Aracı Olarak İnovasyon Stratejileri: Kocaeli Otel İşletmeleri Üzerine Bir Araştırma. Abant İzzet Baysal Üniversitesi, Sosyal Bilimler Enstitüsü Dergisi, 13(2), 101-132.

ÇAKIR, E. (2016), "Electronic Document Management System (EDMS) Software Selection with Fuzzy COPRAS Method: A Municipal Case", W. Sayers ve M. Avc1 (Ed.), Law and Order in Turkish Society içinde (ss. 92-100). Berlin: AGP Research.

ÇETINKAYA, Ö. (2006). Rekabet Stratejilerinin Belirlenmesinde Portföy Analizi ve TARIŞ Üzerine Bir Araştırma. Gazi Üniversitesi İI.̇.B.F. Dergisi, 8(3), 57-76.

DADELO, S., TURSKIS, Z., ZAVADSKAS, E., DADELIENE, R. (2012). Multiple Criteria Assessment of Elite Security Personal on The Basis of ARAS and Expert Methods", Economic Computation and Economic Cybernetics Studies and Research, 46 (4), 65-88.

DESS, G. D., DAVIS, P. S. (1984). Porter's (1980), “ Generic Strategies as Determinants of Strategic Group Membership and Organizational Performance", Academy of Management Journal, C.27 S.3, 467-488.

ECER, F. (2016). "ARAS Yöntemi Kullanılarak Kurumsal Kaynak Planlaması Yazılımı Seçimi”, Uluslararası Alanya İşletme Fakültesi Dergisi, 8 (1), 89-98.

GUNASEKARAN A., KOBU, B, (2007). "Performance Measures And Metrics in Logistics And Supply Chain Management: A Review Of Recent 


\section{S. KORUCUK}

Literature (1995-2004) For Research And Applications", International Journal of Production Research, S. 45 (12), 2819-2840.

HILL, C. W., JONES, G. R. (2009). "Essentials of Strategic Management", Cengage Learning, USA.

KAKLAUSKAS, A., E.K. ZAVADSKAS, S. RASLANAS, R. GINEVICIUS, A. KOMKA., P. MALINAUSKAS, (2006), "Selection of Low-E Windows in Retrofit of Public Buildings By Applying Multiple Criteria Method COPRAS: A Lithuanian Case", Energy and Buildings, 38 (5), 454-462.

KAPLANOĞLU, E, (2018), “ARAS VE COPRAS Yöntemleriyle Nakit Akışına Dayalı Performans Ölçümü: BİST Kimya, Petrol, Kauçuk ve Plastik Ürünler Sektöründe Bir Uygulama”, Muhasebe ve Vergi Uygulamaları Dergisi (MUVU), 11/2, 153-184.

KERŠULIENE, V., ZAVADSKAS, E. K., TURSKIS, Z. (2010), "Selection of Rational Dispute Resolution Method by Applying New Step-Wise Weight Assessment Ratio Analysis (SWARA)", Journal of Business Economics and Management, 11(2), 243-258.

KOUCHAKSARAEI, R. H., ZOLFANI, S. H., GOLABCHI, M. (2015). "Glasshouse Locating Based On SWARA-COPRAS Approach", International Journal of Strategic Property Management, 19(2), 111-122.

KUTUT, V., ZAVADSKAS, E. K., LAZAUSKAS, M. (2014).” Assessment of Priority Options for Preservation of Historic City Centre Buildings using MCDM (ARAS)", Procedia Engineering, 57: 657-661.

MAVI, R,K, GOH, M., ZARBAKHSHNIA, N, (2017), “ Sustainable Third-Party Reverse Logistic Provider Selection with Fuzzy SWARA and Fuzzy MOORA in Plastic Industry", The International Journal of Advanced Manufacturing Technology, 1-18.

MOUSAVI-NASAB, S, H., SOTOUDEH-ANVARI, A, (2017), “A Comprehensive MCDM- Based Approach Using TOPSIS, COPRAS and DEA as an Auxiliary Tool for Material Selection Problems", Materials \& Design, 121, 237253.

MULLINER, E, MALYS, N., MALIENE, V, (2016), “Comparative Analysis of MCDM Methods for the Assessment of Sustainable Housing Affordability", Omega, 59, 146-156.

NEZHAD, M. R. G., ZOLFANI, S. H., MOZTARZADEH, F., ZAVADSKAS, E. K, BAHRAMI, M. (2015)." Planning The Priority of High Tech Industries Based on SWARA-WASPAS Methodology: The Case of The 
Nanotechnology Industry in Iran", Economic Research-Ekonomska Istrazivanja, 28(1), 1111-1137.

NGUYEN, H.T., S.Z.M. DAWAL, Y. NUKMAN, H. AOYAMA, (2014), "A Hybrid Approach for FuzzyMulti-Attribute Decision Making in Machine Tool Selection with Consideration of the Interactions of Attributes", Expert Systems with Applications, 41(6), 3078-3090.

OFLAZOĞLU, S., KOÇAK. A. (2012). "Stratejik Yönlülüklerin Yenilik ve Performans Üzerindeki Etkisi. Çankırı Karatekin Üniversitesi İktisadi ve İdari Bilimler Fakültesi Dergisi, 1(2), 121-144.

ÖMÜRBEK, N, EREN, H., DAĞ, O, (2017), "Entropi-Aras ve EntropiMoosra Yöntemleri İle Yaşam Kalitesi Açısından AB Ülkelerinin Değerlendirilmesi”, Ömer Halisdemir Üniversitesi, İktisadi ve İdari Bilimler Fakültesi Dergisi, Cilt-Sayı: 10(2), 29-48.

ÖZBEK, A, (2017), "Çok Kriterli Karar Verme Yöntemleri ve Excel İle Problem Çözümü, Kavram-Teori-Uygulama”, Seçkin Yayıncılık, Ankara.

PODVEZKO, V. (2011), "The Comparative Analysis of MCDA Methods SAW and COPRAS", Inzinerine Ekonomika-Engineering Economics, 22(2), 134146.

POPOVIC, G., D. STANUJKİC., S. STOJANOVIC (2012), "Investment Project Selection by Applying COPRAS Method and Imprecise Data", Serbian Journal of Management, 7(2), 257-269.

PORTER, M. (1998). "Competitive Strategy Techniques for Analyzing Industries and Competitors", The Free Press, New York.

PORTER, M. E. (2000). "Rekabet Stratejileri Sektör ve Rakip Analizi Teknikleri”, (Çev.: Gülen Ulubilgen). İstanbul: Sistem Yayınları.

RUZGYS, A., VOLVAČİVAS, R., IGNATAVIČİIUS, Č., TURSKIS, Z. (2014). "Integrated Evaluation of External Wall Insulation in Residential Buildings Using SWARA-TODIM MCDM Method", Journal of Civil Engineering and Management, 20(1), 103-110.

Sliogeriene, J., Turskis, Z. \& Streimikiene, D. (2013). Analysis and choice of energy generation technologies: The multiple criteriaaassessment on the case study of Lithuania. Energy Procedia, 32, 11-20.

STANIUNAS, M., M. MEDINECKIENE, E.K. ZAVADSKAS, D. KALIBATAS (2013), “To Modernize or Not: Ecological-Economical Assessment 


\section{S. KORUCUK}

of Multi-Dwelling Houses Modernization", Archives of Civil and Mechanical Engineering, 13(1), 88-98.

STANUJKIC, D., KARABASEVIC, D., ZAVADSKAS, E. K. (2015). “A Framework For The Selection of A Packaging Design Based on The SWARA Method”, Inzinerine Ekonomika-Engineering Economics, 26(2), 181-187.

SUŠINSKAS, S., ZAVADSKAS., E. K., TURSKIS, Z. (2011). "Multiple Criteria Assessment of Pile-Columns Alternatives", Baltic Journal of Road \& Bridge Engineering, 6(3): 77-83.

TAO, X., (2009). "Performance Evaluation Of Supply Chain Based On Fuzzy Matter-Element Theory", International Conference On Information Management, Innovation Management And Industrial Engineering.

TRIANTAPHYLLOU, E. (2000). "Multi-Criteria Decision Making Methods: A Comparative Study", Kluwer Academic Publishers, Dordrecht.

TUŞ IŞIK, A., AYTAÇ ADALI, E. (2016). “A New Integrated Decision Making Approach Based on SWARA and OCRA Methods For The Hotel Selection Problem", International Journal of Advanced Operations Management, 8(2), 140 151.

YILDIRIM, B.F. (2015). "Çok Kriterli Karar Verme Problemlerinde ARAS Yöntemi”, Kafkas Üniversitesi İktisadi ve İdari Bilimler Fakültesi Dergisi, 6 (9), 285-296.

Yurdoğlu, H., ve Kundakc1, N, (2017), "SWARA ve WASPAS Yöntemleri ile Sunucu Seçimi”, Balıkesir Üniversitesi Sosyal Bilimler Enstitüsü Dergisi. Vol. 20 Say1 38, 253-269.

UYGURTÜRK, H, (2016), "Girişim Sermayesi Yatırım Ortaklıklarının Likidite ve Karlılık Performanslarının COPRAS Yöntemi İle Analizi”, Hitit Üniversitesi Sosyal Bilimler Enstitüsü Dergisi, 9/2,637-650.

ÜLGEN, H., MIRZE, S,K, (2004), “İşletmelerde Stratejik Yönetim”, Literatür Yayınları, No:113, İstanbul

VAFAEIPOUR, M., ZOLFANI, S. H., VARZANDEH, M. H. M., DERAKHTI, A., KESHAVARZ, M. E. (2014), "Assessment of Regions Priority for Implementation of Solar Projects in Iran: New Application of a Hybrid MultiCriteria Decision Making Approach", Energy Conversion and Management, 86, 653-663.

VALIPOUR, A, YAHAYA, N, MD NOOR, NORHAZILAN, ANTUCHEVICIENE, J., TAMOSAITIENE, J, (2017), "Hybrid SWARA- 
COPRAS Method for Risk Assessment in Deep Foundation Excavation Project: An Iranian Case Study", Journal of Civil Engineering and Management, 23/4, 524-532.

ZAVADSKAS, E.K., A. KAKLAUSKAS, Z. TURSKIS, J. TAMOSAITIENE, (2008), "Contractor Selection Multi- Attribute Model Applynig COPRAS Method With Grey Interval Numbers", International Conference 20th EURO Mini Conference "Continuous Optimization and Knowledge-Based Technologies” (EurOPT-2008), 20-23 May 2008, Neringa, Lithuania, 241-247.

ZAVADSKAS, E. K, TURSKIS, Z., VILUTIENE, T. (2010).“Multiple Criteria Analysis of Foundation Instalment Alternatives by Applying Additive Ratio Assessment (ARAS) method", Archives of Civil and Mechanical Engineering 10, (3): 123-141.

ZAVADSKAS, E.K., TURSKIS, Z. (2010). "A New Additive Ratio Assessment (ARAS) Method in Multicriteria Decision-Making", Technological and Economic Development of Economy, 16 (2), 159-172.

ZOLFANI, S. H., BAHRAMI, M. (2014). "Investment Prioritizing in High Tech Industries Based on SWARA-COPRAS Approach", Technological \& Economic Development of Economy, 20 (3), 534-553.

ZOPOUNIDIS, C. (1999). “ Multicriteria Decision Aid and in Financial Management”, European Journal of Operational Research,119 (2), 404-415. 


\section{S. KORUCUK}

\section{EKLER}

EK:1 Genel Siralamanın Hesaplanması

\begin{tabular}{|c|c|c|c|c|c|c|c|c|c|c|c|c|c|}
\hline $\begin{array}{c}\text { Ölçüt } \\
\text { Adı }\end{array}$ & $\mathbf{K A V}_{\mathbf{1}}$ & $\mathbf{K A V}_{2}$ & $\mathbf{K A V}_{3}$ & $\mathbf{K A V}_{4}$ & $\mathbf{K A V}_{5}$ & $\mathrm{KAV}_{6}$ & $\mathbf{K A V}_{7}$ & $\mathbf{K A V}_{8}$ & $\mathbf{K A V}_{\mathbf{9}}$ & $\mathbf{K A V}_{10}$ & $\mathbf{K A V}_{11}$ & $\mathrm{KAV}_{12}$ & $\begin{array}{c}\text { Geo. } \\
\text { Ortalama }\end{array}$ \\
\hline $\mathbf{K}_{1}$ & 2 & 1 & 2 & 3 & 4 & 2 & 9 & 3 & 2 & 6 & 4 & 5 & 3,039 \\
\hline $\mathbf{K}_{2}$ & 3 & 2 & 7 & 2 & 5 & 1 & 8 & 2 & 4 & 7 & 5 & 1 & 3,146 \\
\hline $\mathbf{K}_{3}$ & 1 & 3 & 3 & 1 & 2 & 3 & 1 & 4 & 1 & 1 & 3 & 2 & 1,817 \\
\hline $\mathbf{K}_{4}$ & 4 & 5 & 5 & 5 & 3 & 4 & 7 & 1 & 5 & 2 & 2 & 3 & 3,415 \\
\hline $\mathbf{K}_{5}$ & 7 & 6 & 8 & 6 & 6 & 6 & 2 & 5 & 3 & 3 & 6 & 4 & 4,818 \\
\hline $\mathbf{K}_{6}$ & 6 & 4 & 9 & 8 & 1 & 5 & 3 & 7 & 6 & 4 & 7 & 8 & 4,999 \\
\hline $\mathbf{K}_{7}$ & 9 & 7 & 1 & 9 & 7 & 9 & 6 & 9 & 7 & 5 & 8 & 9 & 6,415 \\
\hline $\mathbf{K}_{8}$ & 8 & 9 & 4 & 4 & 9 & 8 & 5 & 8 & 8 & 9 & 9 & 6 & 6,959 \\
\hline $\mathbf{K}_{\mathbf{9}}$ & 5 & 8 & 6 & 7 & 8 & 7 & 4 & 6 & 9 & 8 & 1 & 7 & 5,684 \\
\hline
\end{tabular}

EK: 2 SWARA Yöntemi Parametrelerin Hesaplanması Karar Verici 1, Karar Verici 2 ve Karar Verici 3 Örneği

\begin{tabular}{|c|c|c|c|c|c|c|c|c|c|c|c|c|}
\hline \multirow[b]{2}{*}{$\begin{array}{c}\text { Genel } \\
\text { Siralama }\end{array}$} & \multicolumn{4}{|c|}{ Karar Verici 1} & \multicolumn{4}{|c|}{ Karar Verici 2} & \multicolumn{4}{|c|}{ Karar Verici 3} \\
\hline & $\mathbf{s}_{\mathbf{j}}$ & $\mathbf{k}_{\mathbf{j}}$ & $\mathbf{d}_{\mathbf{j}}$ & $\mathbf{w}_{\mathbf{j}}$ & $\mathbf{s}_{\mathbf{j}}$ & $\mathbf{k}_{\mathbf{j}}$ & $\mathbf{d}_{\mathbf{j}}$ & $\mathbf{w}_{\mathbf{j}}$ & $\mathbf{s}_{\mathbf{j}}$ & $\mathbf{k}_{\mathbf{j}}$ & $d_{j}$ & $\mathbf{w}_{\mathrm{j}}$ \\
\hline $\mathbf{K}_{3}$ & - & - & 1,000 & 0,151 & - & - & 1,000 & 0,165 & - & - & 1 & 0,164 \\
\hline $\mathbf{K}_{1}$ & 0,05 & 1,05 & 0,952 & 0,144 & 0,10 & 1,10 & 0,909 & 0,150 & 0,05 & 1,05 & 0,952 & 0,156 \\
\hline $\mathbf{K}_{2}$ & 0,05 & 1,05 & 0,907 & 0,137 & 0,10 & 1,10 & 0,826 & 0,136 & 0,15 & 1,15 & 0,828 & 0,136 \\
\hline $\mathbf{K}_{4}$ & 0,10 & 1,10 & 0,825 & 0,125 & 0,10 & 1,10 & 0,751 & 0,124 & 0,15 & 1,15 & 0,720 & 0,118 \\
\hline $\mathbf{K}_{5}$ & 0,10 & 1,10 & 0,750 & 0,113 & 0,15 & 1,15 & 0,653 & 0,108 & 0,10 & 1,10 & 0,655 & 0,107 \\
\hline $\mathrm{K}_{6}$ & 0,15 & 1,15 & 0,652 & 0,098 & 0,05 & 1,05 & 0,622 & 0,103 & 0,10 & 1,10 & 0,595 & 0,097 \\
\hline $\mathbf{K}_{9}$ & 0,10 & 1,10 & 0,593 & 0,090 & 0,20 & 1,20 & 0,519 & 0,086 & 0,15 & 1,15 & 0,518 & 0,085 \\
\hline $\mathbf{K}_{7}$ & 0,20 & 1,20 & 0,494 & 0,075 & 0,25 & 1,25 & 0,415 & 0,068 & 0,20 & 1,20 & 0,431 & 0,071 \\
\hline $\mathbf{K}_{8}$ & 0,10 & 1,10 & 0,449 & 0,068 & 0,15 & 1,15 & 0,361 & 0,060 & 0,05 & 1,05 & 0,411 & 0,067 \\
\hline
\end{tabular}

EK: 3 ARAS Yöntemi Başlangıç Karar Matrisi

\begin{tabular}{|c|c|c|c|c|c|c|c|c|c|}
\hline & Min & Mak & Mak & Mak & Mak & Mak & Mak & Mak & Min \\
\hline & $\mathbf{K}_{\mathbf{1}}$ & $\mathbf{K}_{\mathbf{2}}$ & $\mathbf{K}_{\mathbf{3}}$ & $\mathbf{K}_{\mathbf{4}}$ & $\mathbf{K}_{\mathbf{5}}$ & $\mathbf{K}_{\mathbf{6}}$ & $\mathbf{K}_{\mathbf{7}}$ & $\mathbf{K}_{\mathbf{8}}$ & $\mathbf{K}_{\mathbf{9}}$ \\
\hline $\mathbf{A}_{\mathbf{1}}$ & 7 & 4 & 5 & 6 & 7 & 3 & 8 & 4 & 3 \\
\hline $\mathbf{A}_{\mathbf{2}}$ & 7 & 5 & 7 & 5 & 8 & 4 & 7 & 7 & 5 \\
\hline $\mathbf{A}_{\mathbf{3}}$ & 5 & 8 & 7 & 3 & 5 & 5 & 7 & 6 & 7 \\
\hline $\mathbf{A}_{\mathbf{4}}$ & 9 & 3 & 6 & 4 & 6 & 6 & 5 & 8 & 6 \\
\hline $\mathbf{A}_{\mathbf{5}}$ & 6 & 7 & 4 & 5 & 4 & 6 & 6 & 9 & 7 \\
\hline $\mathbf{A}_{\mathbf{0}}$ (Optimal) & 5 & 8 & 7 & 6 & 8 & 6 & 8 & 9 & 3 \\
\hline
\end{tabular}


EK: 4 COPRAS Yöntemi Başlangıç Karar Matrisi

\begin{tabular}{|c|c|c|c|c|c|c|c|c|c|}
\hline & $\mathbf{K}_{\mathbf{1}}$ & $\mathbf{K}_{\mathbf{2}}$ & $\mathbf{K}_{\mathbf{3}}$ & $\mathbf{K}_{\mathbf{4}}$ & $\mathbf{K}_{\mathbf{5}}$ & $\mathbf{K}_{\mathbf{6}}$ & $\mathbf{K}_{\mathbf{7}}$ & $\mathbf{K}_{\mathbf{8}}$ & $\mathbf{K}_{\mathbf{9}}$ \\
\hline $\mathbf{A}_{\mathbf{1}}$ & 3 & 2 & 3 & 4 & 5 & 4 & 2 & 3 & 2 \\
\hline $\mathbf{A}_{\mathbf{2}}$ & 4 & 3 & 3 & 4 & 4 & 5 & 3 & 2 & 3 \\
\hline $\mathbf{A}_{\mathbf{3}}$ & 2 & 4 & 4 & 5 & 5 & 3 & 4 & 5 & 4 \\
\hline $\mathbf{A}_{\mathbf{4}}$ & 5 & 2 & 2 & 1 & 2 & 1 & 3 & 2 & 1 \\
\hline $\mathbf{A}_{\mathbf{5}}$ & 4 & 3 & 3 & 2 & 3 & 3 & 2 & 4 & 2 \\
\hline Yön & - & + & + & + & + & + & + & + & - \\
\hline
\end{tabular}

